\title{
ACESSO QUALIFICADO À JUSTIÇA DO TRABALHO: INCLUSÃO SOCIAL PELA TUTELA COLETIVA
}

Ricardo José Macedo de Britto Pereira*

\begin{abstract}
Resumo:
$\mathrm{O}$ estudo desenvolve o conceito de acesso qualificado à justiça no intuito de impulsionar a tutela coletiva dos direitos sociais dos trabalhadores. $\mathrm{O}$ acesso qualificado à justiça propicia maior participação social e transformação das relações de poder, aprimorando o processo democrático. O objetivo é estabelecer, por meio de pesquisa bibliográfica, as bases gerais para a consolidação do acesso qualificado à justiça na justiça do trabalho. $\mathrm{O}$ resultado apresenta as condições para a consolidação da tutela coletiva, por meio do acesso qualificado à justiça, como instrumento essencial para combater as violações à Constituição e às leis no âmbito trabalhista.
\end{abstract}

Palavras-chave:

Acesso à justiça; acesso qualificado; tutela coletiva; reforma estrutural; justiça do trabalho

\section{QUALIFIED ACCESS TO JUSTICE: SOCIAL INCLUSION THROUGH COLLECTIVE ADJUDICATION}

\begin{abstract}
:
The study deals with the concept of qualified access to justice to stimulate the collective protection of workers' social rights. Qualified access to justice provides greater social participation and transformation of power relations, improving the democratic process. The objective is to establish, through bibliographic research, the general bases for the consolidation of qualified access to justice in labor justice. The result presents the conditions for the consolidation of collective protection, through qualified access to justice, as an essential instrument to combat violations of the Constitution and laws in the labor field.
\end{abstract}

Keywords:

Access to justice; qualified access; collective adjudication; structural reform; labor justice

\section{INTRODUÇÃO}

O presente estudo se ocupa de considerações gerais sobre o acesso qualificado à justiça. A ideia é ressaltar todo o potencial da ação e da tutela coletivas para a

\footnotetext{
* Professor Titular e Pesquisador do Mestrado das Relações Sociais e Trabalhistas do Centro Universitário do Distrito Federal - UDF. Doutor pela Universidade Complutense de Madri. Visiting Fellow na Universidade de Cornell-NY EUA (2017-2018). Master of Law na Universidade de Syracuse-NY EUA. Mestre pela UNB. Colíder do Grupo e Pesquisa Trabalho, Constituição e Cidadania (UNB/CAPES). rjmbpereira@ gmail.com.
} 
concretização dos valores constitucionais e dos direitos de todo o ordenamento jurídico.

$\mathrm{O}$ acesso qualificado à justiça é abordado como elemento propulsor de maior participação social e transformação nas relações de poder e, consequentemente, de aprimoramento do processo democrático. A Constituição brasileira de 1988 incluiu em seu texto vários instrumentos coletivos e reforçou o poder dos atores legitimados para manejá-los.

A temática é examinada a partir de um enfoque geral, mas com ênfase em pontos relativos ao acesso coletivo à justiça do trabalho e da intersecção dos processos de especificação dos direitos no âmbito laboral.

O objetivo é questionar o tratamento individual ou fragmentado de situações que envolvem coletividades de trabalhadores, ou também o tratamento coletivo, mas que não explora toda a potencialidade dos instrumentos coletivos para a realização dos valores constitucionais.

O avanço da tutela coletiva, por meio do acesso qualificado à justiça, apresenta-se essencial para combater as graves violações à Constituição e às leis no âmbito trabalhista.

O texto está dividido nos seguintes tópicos: conceito de acesso qualificado à justiça; direito fundamental de acesso à justiça; e acesso qualificado à justiça do trabalho.

\section{CONCEITO DE ACESSO QUALIFICADO À JUSTIÇA}

A expressão "acesso qualificado à justiça” é uma designação ampla na qual podem se encaixar vários significados. Daí a necessidade de se precisar o seu conceito, na forma como utilizada no presente estudo. $\mathrm{O}$ acesso qualificado à justiça diz respeito ao acesso coletivo. Contudo, isso não significa que haja contraposição ao acesso individual. Denominar o acesso coletivo como "qualificado" não significa "desqualificar" o acesso individual. Pelo contrário, reconhece-se a relevância do acesso individual à justiça como elemento essencial à efetividade dos valores e bens constitucionais.

O termo "qualificado" é utilizado em contraposição a uma abordagem meramente "quantitativa" do acesso coletivo. Ou seja, o acesso coletivo propicia, inquestionavelmente, a tutela de direitos a um número maior de pessoas, porém, não se trata de uma questão meramente numérica. Por esta via, permite-se a apreensão autêntica do conflito ou de toda a situação que se apresenta em desconformidade com o ordenamento 
jurídico. Neste aspecto, individualizar questões que dizem respeito ao coletivo para oferecer respostas fragmentadas mostra-se não apenas insuficiente, mas também desvirtuado, na medida em que restringe o acesso aos bens e valores previstos no ordenamento jurídico. $\mathrm{O}$ tratamento de violações em massa como se fossem individuais fragiliza as respostas e preserva as situações de desconformidade com a Constituição e as leis. Em contextos de extrema desigualdade, a negação ou restrição ao acesso qualificado à justiça reproduz os obstáculos para o acesso aos direitos por grupos mais vulneráveis.

Portanto, o acesso qualificado à justiça apresenta-se como instrumento adequado de promoção de transformações sociais, mediante a participação ampla e redistribuição de poderes pela via do acesso aos bens da vida, sobretudo pelos grupos menos favorecidos, constituindo elemento essencial para o aprimoramento do processo democrático.

$\mathrm{O}$ acesso qualificado pode ser abordado a partir da perspectiva de reforma estrutural. Owen Fiss afirma que os valores e direitos constitucionais dão ensejo a interpretações variadas e, por vezes, ambíguas, sendo necessário definir o sentido desses direitos, dotando-os de "conteúdo operacional", para eleger as prioridades nos conflitos existentes. A significação dos valores constitucionais é tarefa de toda a sociedade, tanto dos indivíduos quanto das instituições, e "determina a qualidade de nossa existência social," cuja dimensão pública resulta da possibilidade de todos terem voz nesse processo. Embora os juízes não tenham o monopólio da atividade de dar sentido aos valores constitucionais, o papel deles nesse processo é de inegável relevância. O processo de decisão, nesta perspectiva da "reforma estrutural", resulta do encontro de atores que dá significado aos valores constitucionais e que coloca toda a burocracia estatal a serviço de sua implementação. Fiss ressalta que a origem da reforma estrutural se encontra na era Warren da Suprema Corte Norte-Americana, mais especificamente em todo o esforço dos órgãos do Judiciário para colocar em prática a regra consagrada no caso Brown v. Board of Education, no sentido de operar as transformações necessárias para "reconstruir a realidade social." (FISS, 2003, p. 3)

A reforma estrutural reformula o método tradicional de resolução de conflitos, mas as disposições estruturais não se confrontam com os direitos, uma vez que também se encontra superada a ideia de que os direitos pressupõem limites à atuação do estado. Os direitos, assim como as normas estruturais, geram e redistribuem poderes, de modo que não há contraposição, mas complementação na concretização dos valores constitucionais. (VAROL, 2017) 


\section{DIREITO FUNDAMENTAL DE ACESSO À JUSTIÇA}

$\mathrm{O}$ acesso à justiça constitui direito da mais alta relevância, na medida em que representa garantia para a efetividade de todos os direitos que integram o ordenamento jurídico. Na Constituição brasileira, esse direito está previsto no artigo $5^{\circ}, \mathrm{XXXV}$, ao dispor que "a lei não excluirá da apreciação do Poder Judiciário lesão ou ameaça a direito".

O direito fundamental de acesso à justiça é fruto de uma longa construção que vem sendo edificada com apoio em diversas disciplinas, como a Sociologia Jurídica, o Direito Constitucional, o Processual, o Internacional, os direitos humanos, entre outras, de modo que sua análise deve espelhar toda a "riqueza de seu conteúdo e não pode conformar-se com uma exposição puramente normativa". O exercício desse direito supõe a institucionalização de procedimentos destinados a conferir proteção aos direitos e resolver os mais variados conflitos "de maneira oportuna e com base no ordenamento jurídico". (HERNÁNDEZ, 2006, p. 18)

A inquestionável centralidade do acesso à justiça no sistema jurídico se associa ao conteúdo bastante variado do direito. É possível divisar, pelo menos como critério de clarificação para considerações sobre a matéria, uma dimensão formal e outra, material. (PEREIRA, 2018).

O acesso formal à justiça consiste na real possibilidade de as demandas dos indivíduos e grupos serem levadas e chegarem ao Judiciário. A despeito da importância do acesso formal, boa parcela de nossa população não está em condições de desfrutá-lo, sobretudo os que são mais carentes de recursos econômicos.

$\mathrm{O}$ acesso formal à justiça, no seu aspecto negativo, representa a garantia de que o percurso até o Judiciário não seja obstado. Neste caso, a eficácia do direito é não só vertical, em relação ao Estado, mas também horizontal, dirigindo-se aos particulares. No âmbito trabalhista, o empregador, por exemplo, não pode impedir o acesso à justiça do trabalhador, tampouco adotar medidas para constranger o seu exercício.

O acesso formal à justiça impõe também algumas ações, como a adoção de providências para a promoção do direito, entre as quais a eliminação dos obstáculos que o inviabilizam. Nesse caso, a eficácia do direito é vertical, ou seja, em relação ao poder público, que deve adotar todas as medidas para remover as dificuldades e facilitar o acesso à justiça 
dos cidadãos, grupos e instituições, tornando-o o mais amplo possível.

Além do acesso formal à justiça, que é de extrema relevância, a Constituição assegura igualmente o acesso material à justiça. É o que se costuma denominar de acesso à “ordem jurídica justa”. (WATANABE, 1988, 129)

O acesso à ordem jurídica justa "requer, antes de mais nada, uma nova postura mental". É necessário "pensar na ordem jurídica e nas respectivas instituições, pela perspectiva do consumidor, ou seja, do destinatário das normas jurídicas, que é o povo". Sendo assim, a interpretação e a aplicação do direito substancial devem ajustar-se à realidade social, uma vez que "para a aplicação de um direito substancial discriminatório e injusto, melhor seria evitar o acesso à justiça, pois assim se evitaria o cometimento de dupla injustiça”. O acesso à justiça pressupõe uma "justiça adequadamente organizada" e pelos “instrumentos processuais aptos à efetiva realização do direito”. (WATANABE, 1988, 129132)

Definir, com exatidão, o que venha a ser ordem jurídica justa é um grande desafio. Até porque o seu conteúdo não é estabelecido de uma vez por todas e com caráter prévio. No marco do estado democrático de direito, as partes interessadas possuem o papel relevante de contribuir ativamente para a construção desse conteúdo. Trata-se de conceito que envolve uma pluralidade de significados e possibilidades, construídas e reconstruídas a todo momento e com a participação de diversos atores.

Outro aspecto relevante do acesso material à Justiça é o direito do autor, bem como do réu, de terem o caso efetivamente resolvido. A abstração do direito de ação foi importante para assegurar o amplo acesso à justiça, mas sua aplicação rigorosa acabou levando a discussões intermináveis acerca de preliminares processuais. A formalização excessiva do processo impede o efetivo acesso à análise do mérito, o que frustra as expectativas dos jurisdicionados. Formalidades são garantias necessárias, mas não como barreiras, praticamente intransponíveis, para se chegar à prestação jurisdicional ${ }^{1}$.

A partir do momento em que a Constituição brasileira de 1988 reuniu inúmeros instrumentos visando proporcionar tutela coletiva a interesses e direitos, as resistências e os obstáculos existentes ao acesso à justiça dos entes legitimados para as ações coletivas constituem grave violação ao direito fundamental previsto no artigo $5^{\circ}, \mathrm{XXXV}$, da

\footnotetext{
${ }^{1} \mathrm{O}$ impulso ao mérito foi uma das providências trazidas pelo Código de Processo Civil de 2015 Art. $4^{\circ}$ As partes têm o direito de obter em prazo razoável a solução integral do mérito, incluída a atividade satisfativa.)
} 
Constituição, bem como a outros dispositivos constitucionais que especificamente preveem tais instrumentos, bem como os entes legitimados para operá-los.

\subsection{Processo de especificação e coletivização dos direitos}

Após a Segunda Guerra Mundial, o processo de internacionalização do direito assume características bem diferenciadas da internacionalização que ocorreu na primeira metade do século XX. Concomitante a esse movimento, surge outro de especificação dos direitos, pelo qual o direito passa a ser considerado vinculado às pessoas com nome $\mathrm{e}$ rosto, inseridas num contexto social. Em lugar de desconsiderar, o direito deve identificar a situação social em que os titulares dos direitos estão inseridos. (AÑON ROIG, 2004, p. 41)

A emergência de direitos específicos se refere a categorias de pessoas em posições minoritárias na sociedade no tocante ao exercício dos direitos, como mulheres, imigrantes e negros. A condição física e mental de determinadas pessoas acarreta desvantagens nas relações sociais, dando origem a direitos das crianças e adolescentes bem como das pessoas com deficiência. O processo de especificação dos direitos também se deu em situações específicas dos indivíduos em relações econômicas, em que a outra parte possui posição preponderante, hegemônica ou de visível superioridade, como no caso dos consumidores e trabalhadores. Trata-se do que a doutrina denomina de "técnica da igualdade como diferenciação; a equiparação é uma meta e a diferenciação uma técnica para alcançar essa equiparação". (AÑON ROIG, 2004, p. 43)

O processo de especificação dos direitos é fundamental para se alcançar cidadania inclusiva e social. Não é possível cogitar de democracia real, sem levar em conta a situação de grupos específicos, que são colocados completamente a margem do sistema e não usufruem dos benefícios e serviços que a coletividade oferece.

A mudança dessa realidade depende de alguma forma de coletivização, até porque "os direitos coletivos são um dado inquestionável da realidade política e jurídica contemporânea e das ciências sociais”. (LÓPEZ CALERA, 2000, p. 17) A coletivização busca revelar a identidade do grupo e não só a identidade individual. (JAUREGUI, 2001, p. 55) Os direitos coletivos não são "uma essência ontológica, mas uma convenção de linguagem que designa o êxito de um processo formalizado de formação da vontade de uma pluralidade organizada de pessoas". (GUIGNI, 2001, p. 60) Não se pode negar a "inevitável (e insuperável) dialética que existe entre a individualidade e a sociabilidade dos seres. A 
alternativa excludente entre uma e outra posição perde sentido ante a unidade dos "processos de individuação e socialização" integrada "nos conceitos fundamentais dos direitos". (HABERMAS, 2000, p. 162) ${ }^{2}$

\subsection{Discussão Sobre a Fundamentalidade dos Direitos Objeto de Tutela Coletiva}

Ressaltam Mauro Cappelletti e Bryant Garth (1988, p. 11) que as modernas constituições asseguram, entre outros direitos, "os direitos ao trabalho, à saúde, à segurança nacional e à educação". Tais direitos, para serem efetivados, dependem da atuação positiva do Estado. $\mathrm{O}$ direito ao acesso à justiça adquiriu especial importância com as reformas do welfare state, na medida em que aos indivíduos são atribuídos novos direitos substantivos, na "qualidade de consumidores, locatários, empregados e, mesmo, cidadãos". Sem o acesso à justiça, "a titularidade de direitos é destituída de sentido, na ausência de mecanismos para sua efetiva reivindicação. $\mathrm{O}$ acesso à justiça pode, portanto, ser encarado como o requisito fundamental - o mais básico dos direitos humanos - de um sistema jurídico moderno e igualitário que pretenda garantir, e não apenas proclamar os direitos de todos."

$\mathrm{Na}$ sociedade contemporânea, é possível identificar novos sujeitos coletivos a partir de grupos, classes ou categorias em razão de fatores como "raça, origem, gênero sexual, nível cultural e de emprego, do consumo de determinado produto, de pertencer a determinada faixa etária, entre outras formas contingenciais e, às vezes, efêmeras de agrupamento". Em geral, encontram-se em "situação desvantajosa, marginalizada ou lhes são atribuídos direitos que necessitam de implementação e concretização, sem que haja, todavia, um representante naturalmente designado para isso". Daí a necessidade de instrumentos jurídicos que possibilitem "a representação do grupo circunstancial em juízo e de uma forma processual em que a decisão final vincule todo o segmento social representado". (LEAL, 1998, p. 33)

A tutela coletiva de interesses e direitos passou a ser uma exigência na sociedade atual, como resposta às mais variadas violações que não se dirigem a uma pessoa determinada, mas à coletividade. Essa tutela foi alçada a direito fundamental, ou seja,

\footnotetext{
2 Habermas, Jürgen pontua que "as pessoas jurídicas só podem chegar a ser indivíduos mediante a socialização, a integridade da pessoa só pode ser protegida quando se protege seu livre acesso às relações interpessoais e às tradições culturais nas que pode manter e conservar sua própria identidade. $\mathrm{O}$ individualismo corretamente entendido está incompleto sem essa chispa de "comunitarismo"”.
} 
elemento essencial e irremovível para assegurar os direitos da coletividade.

A partir dessa conclusão, indaga-se se os direitos, objeto de tutela coletiva, independentemente de sua posição no ordenamento jurídico, seriam direitos fundamentais?

A doutrina vem dando pouca atenção a essa relevante questão. Em geral, invocam-se as gerações dos direitos fundamentais, para incluir os direitos difusos e coletivos na terceira geração. Mas essa consideração não responde à pergunta anteriormente formulada.

A Constituição de 1988, como referido, contém, no artigo $5, \S 2^{\circ}$, cláusula de abertura para os direitos decorrentes do regime e dos princípios adotados e dos tratados internacionais de que o Estado brasileiro seja parte no rol de direitos fundamentais. A mesma cláusula de abertura é especificamente prevista para os direitos sociais dos trabalhadores, no caput do artigo $7^{\circ}$, ao enumerar os direitos sociais dos trabalhadores urbanos e rurais, além de outros que visem a melhoria de sua condição social.

A tutela processual dos interesses e direitos difusos, coletivos e individuais homogêneos remete à sua dimensão material, de acordo com sua previsão no ordenamento jurídico. Esses interesses e direitos podem estar contidos em normas constitucionais ou infraconstitucionais. Algumas normas infraconstitucionais desfrutam do caráter de fundamentalidade, como as referidas à saúde, higiene e segurança, em razão das referidas cláusulas constitucionais de abertura do rol de direitos fundamentais.

Ainda que não se defenda que a tutela coletiva seja capaz de converter todos os interesses e direitos passíveis de serem nela veiculados em fundamentais, as violações que afetam a coletividade, tanto pela abrangência quanto pela frequência, assumem considerável gravidade, que podem dar ensejo a sanções diferenciadas das aplicadas, caso a violação se restringisse à esfera individual. Daí que a reação a essas violações é dotada de maior contundência e se apresenta adequada à ideia de direito fundamental.

Como esclarece, apropriadamente, Ronaldo Lima dos Santos (2015, p. 391):

[a] nota da transindividualidade possui o poder da transmutação jurídica, uma vez que muitos direitos tradicionalmente considerados de uma dimensão, ao serem transpostos para o plano dos interesses transindividuais recebem uma nova configuração jurídica, principalmente com a agregação do valor da solidariedade.

Adiante, complementa:

No âmbito da transindividualidade, até mesmo os direitos historicamente 
classificados ou tipificados como individuais são revestidos pela solidariedade. Os interesses individuais homogêneos, por exemplo, trazem a nota da solidariedade, à medida que constituem uma forma de tutela coletiva de pretensões individuais. Trazem a concepção de que os direitos individuais podem ligar-se a outros interesses, sem perder a nota da individualidade e da exclusividade. Sob a ótica da transindividualidade, os interesses individuais homogêneos representam a perda do caráter egoístico dos interesses individuais, dando ensejo ao nascimento de laços de união e reciprocidade de direitos que continuam independentes, mas que se unem, fortalecendo-se reciprocamente, formando uma relação de responsabilidade por pessoas que passam a estar unidas por um interesse comum, de modo que cada indivíduo sente-se na obrigação de apoiar os outros.

Gregório Assagra de Almeida (2013, p. 25) cogita de uma fundamentalidade decorrente das circunstâncias concretas da violação ao direito. Segundo o autor, há casos em que o direito não é fundamental, mas, diante de circunstâncias concretas, pode estar vinculado a uma questão vital, de modo que sua proteção passa a desfrutar de uma fundamentalidade.

$\mathrm{O}$ acesso qualificado a direitos, por meio da tutela coletiva para propiciar a inclusão social das classes menos favorecidas, com a transformação de relações de poder, possui um inquestionável caráter de fundamentalidade, ainda que os direitos não integrem o rol de direitos fundamentais.

\subsection{Integridade da Dimensão Coletiva}

O conjunto normativo que regula a tutela coletiva utiliza os termos interesses e direitos como sinônimos. Como esclareceram os elaboradores do anteprojeto do Código de Defesa do Consumidor:

A necessidade de estar o direito subjetivo sempre referido a um titular determinado ou ao menos determinável impediu por muito tempo que os 'interesses' pertinentes, a um tempo, a toda uma coletividade e a cada um dos membros dessa mesma coletividade, como, por exemplo, os 'interesses' relacionados com o meio ambiente, à saúde, à educação, à qualidade de vida etc., pudessem ser havidos por juridicamente protegíveis. Era a estreiteza da concepção tradicional do direito subjetivo, marcada profundamente pelo liberalismo individualista, que obstava a essa tutela jurídica. Com o tempo, a distinção doutrinária entre 'interesses simples' e 'interesses legítimos' permitiu um pequeno avanço, com a outorga de tutela jurídica a estes últimos. Hoje, com a concepção mais larga do direito subjetivo, abrangendo também do que outrora se tinha como mero 'interesse' na ótica individualista então predominante, ampliou-se o espectro da tutela jurídica e jurisdicional.(GRINOVER, 2004, p. 800)

Segundo o parágrafo único do artigo 81 da Lei 8.078 de 11.09.1990, os interesses ou direitos difusos são transindividuais, indivisíveis e com titulares indeterminados 
que se vinculam por circunstâncias fáticas; os interesses ou direitos coletivos são transindividuais, indivisíveis, titularizados por grupos vinculados juridicamente entre si ou com a parte contrária; e que os interesses ou direitos individuais homogêneos são "decorrentes de origem comum".

Portanto, o dispositivo citado prevê interesses e direitos em que seus titulares são indeterminados, determináveis ou determinados e de natureza indivisível ou divisível. No entanto, todos eles são espécie do gênero coletivo, de modo que há uma linha comum entre eles, pela qual em todas as espécies há algum grau, ou momento, de indeterminação e de indivisibilidade, sendo, obviamente, mais acentuado nos direitos e interesses difusos e menos, nos individuais homogêneos. Da mesma forma, há possibilidade de determinação e particularização em todos eles, evidentemente com maior intensidade nos individuais homogêneos e menor, nos difusos. Em relação aos individuais homogêneos, podese dizer que a situação fática é considerada em seu conjunto, em razão da origem comum, mas comporta reparação divisível e determinada.

A tutela coletiva é a resposta prevista no ordenamento jurídico para a defesa de interesses e direitos coletivos e pressupõe a percepção macro dos fenômenos, por meio da qual se busca a dimensão integral dos conflitos, das lesões, bem como dos direitos e interesses envolvidos.

A dificuldade de enquadramento em uma ou outra categoria de interesses e direitos não pode servir de obstáculo para a determinação de providências necessárias à resolução de problemas que envolvem coletividades de pessoas. A tutela coletiva não comporta delimitações precisas, em razão das múltiplas possibilidades que sua consideração gera. As categorias de interesses e direitos previstas na Lei 8.078/1990 são identificadas a partir de parâmetros formais genéricos, mesmo porque não poderia o legislador estabelecer rol exaustivo para enquadramento preciso das situações concretas em cada uma delas, nem seria conveniente fazê-lo para não restringir.

Além do mais, pelo que está disposto na lei, deveria ser possível realizar o enquadramento nas categorias enumeradas, mediante análise do tipo de direito ou interesse de que se trata, ou seja, no plano do direito material. Porém, a doutrina defende que "a correta distinção entre eles depende da correta fixação do objeto litigioso do processo (pedido e causa de pedir)". Acrescenta Watanabe:

É justamente "na transposição do conflito de interesses do plano extraprocessual 
para o processual e na formulação do pedido de provimento jurisdicional que são cometidos vários equívocos. A tutela de interesses 'coletivos' tem sido tratada, por vezes, como tutela de interesses ou direitos 'individuais homogêneos', e a de interesses ou direitos 'coletivos', que por definição legal são de natureza indivisível, tem sido limitada a um determinado segmento geográfico da sociedade, com uma inadmissível atomização de interesses ou direitos de natureza indivisível." (GRINOVER, 2004, p. 807)

$\mathrm{Ou}$ seja, prevalece o entendimento de que o enquadramento desses interesses e direitos só é possível na sua fase processual, de acordo com a providência reivindicada pelo legitimado para a ação. Evidentemente, a matéria costuma dar margem a dificuldades e intensas controvérsias, mas que não justificam o dispêndio de energia e tempo na questão formal das categorias em espécie, para colocar em plano secundário a tutela de interesses e direitos integrantes do gênero coletivo. ${ }^{3}$

As variações conceituais se verificam também em outros aspectos. O termo coletivo pode ser utilizado para se referir ao interesse pessoal do grupo como entidade, com indiretas repercussões na coletividade. Neste caso, o interesse coletivo assim o é pelo simples fato de vincular-se a um sujeito coletivo. O sentido usual, porém, é que o interesse coletivo se refira diretamente aos integrantes do grupo. Se tratado como soma de interesses individuais, é possível individualizar as situações, o que pode levar à fragmentação da solução dos problemas, com o comprometimento da tutela coletiva. Daí que o correto seja considerar o interesse coletivo como síntese e não soma de situações individuais. Os genuínos interesses coletivos dão origem a nova realidade, diversa da soma dos interesses individuais. Os interesses coletivos são defendidos por grupos, o que pressupõe organização e ajuste de pretensões individuais. Consequentemente, não comportam trato por parcelas, pois exigem respostas para o conjunto da situação.

A posição de que se trata de uma síntese e não soma de interesses individuais não chega ao ponto do desaparecimento das individualidades que o formam. $\mathrm{O}$ âmbito do coletivo, ainda que não coincida com a reunião das diversas partes que o compõem, não passa a ter vida própria desvinculada das individualidades que o concebem. A autonomia absoluta do coletivo levaria à coletivização radical, que as experiências históricas se encarregaram de mostrar sua incompatibilidade com o Estado de Direito. A anulação ou o

\footnotetext{
${ }^{3}$ Essa é a posição do Supremo Tribunal Federal, por exemplo, no RE 163.231, DJ de 29.06.2001; RE 213.015-0, DJ de 24/05/2002.
} 
desaparecimento dos sujeitos que fundam a coletividade acarretariam a própria perda de identidade do grupo. Os interesses coletivos são formulações linguísticas e resultam de processos comunicacionais, de modo que sua tutela só é adequada se associada aos princípios democráticos.

A tutela dos interesses coletivos se opera por fórmulas variadas, o que reforça a ideia primordial de resolver problemas que afetam grupos e categorias de pessoas, sem exigências de precisão quanto à forma e ao instrumento de formulação da demanda. A legitimação é concorrente, indicando que a efetividade dos interesses e direitos coletivos não é tarefa de um único ator, mas resultado de empenho coletivo para lograr resultados concretos. O artigo 83 da Lei 8.078/1990 estabelece que para a defesa dos direitos e interesses protegidos por este código são admissíveis todas as espécies de ações capazes de propiciar sua adequada e efetiva tutela".

Os interesses e direitos individuais homogêneos não deixam de ser titularizados pela coletividade, indivisivelmente considerada. O pedido deduzido em ação coletiva para a defesa de direitos individuais homogêneos persegue a tutela indivisível do bem, que se traduzirá numa condenação global (genérica). É somente nas fases de liquidação e execução que a divisibilidade passa a evidenciar-se.

Há uma tendência de se problematizar o conceito de origem comum, para excluir categorias de interesses e direitos do âmbito da tutela coletiva. Corresponderia essa origem comum à prática de um único ato ou ela pode se caracterizar mesmo diante da prática de atos sucessos? Trata-se, na verdade, de um falso problema, forjado para restringir a tutela coletiva. É nesse propósito que passaram a ser cunhadas expressões como interesses individuais puros, simples ou heterogêneos.

A origem comum, como indicadora da homogeneidade, para fins de tutela coletiva, se faz presente pelo simples fato de a tutela coletiva proporcionar vantagens na satisfação dos interesses e direitos vulnerados. A ausência de homogeneidade, que afastaria a tutela coletiva, é somente aquela decorrente de situações tão díspares, a ponto de praticamente inviabilizar a tutela coletiva desses interesses e direitos.

Em outras palavras, o conceito de origem comum não é fático e sim normativo. Assim também se dá com o conceito de indivisibilidade e de indisponibilidade. São conceitos relevantes para a tutela coletiva. A diferença entre localizá-los no campo normativo, e não no fático, é que o ponto central de análise não é identificar se determinada 
situação comporta fragmentação ou se uma vantagem possa ser objeto de disposição por seu titular. Isso porque não se está no âmbito do ser. A questão é se o tratamento individual de determinada situação ou bem satisfará as necessidades da coletividade de forma adequada ou se a disposição de uma situação de vantagem causará prejuízos sociais. No âmbito normativo, deve-se avaliar os prejuízos sociais que decisões e propostas de soluções individualizadas provocam, em razão da não observância do ordenamento jurídico, principalmente dos princípios constitucionais.

As abordagens no campo fático que levam à divisibilidade, disponibilidade e não homogeneidade dos interesses e direitos resgatam categorias tradicionais que, definitivamente, não são mais adequadas para a resolução real de muitos dos problemas atuais, embora sejam utilizadas em grande escala.

Por outro lado, não há óbice a que interesses ou direitos difusos, coletivos ou individuais homogêneos sejam objeto de ação individual, no que diz respeito a situação particularizada de cada vítima. Esse fato não compromete o caráter coletivo desses interesses e direitos a ser tutelado pela ação civil pública. Por tal razão é que, a rigor, constitui impropriedade a afirmação de que os titulares dos interesses e direitos difusos são pessoas indeterminadas, como faz a Lei 8.078/1990. Os titulares desses interesses e direitos são as comunidades e coletividades e não as pessoas indeterminadas que delas fazem parte. A indivisibilidade refere-se a essa titularidade. (GIDI, 1995, p. 22)

Em síntese, não há diferenças entre as categorias interesses e direitos para fins de tutela coletiva; as dificuldades de realizar enquadramento preciso das violações ao ordenamento jurídico nas categorias previstas de interesses e direitos coletivos não acarretam a restrição da tutela, mas, ao contrário, justificam sua ampliação, desde que a situação se inclua no gênero coletivo; e a tutela coletiva está a cargo de vários atores e não se condiciona a forma específica, podendo se realizar por qualquer instrumento.

Na esfera trabalhista, Nelson Nery Junior (2000, p. 599) ressalta o pioneirismo da Consolidação das Leis do Trabalho na tutela dos interesses e direitos transindividuais em juízo, por meio da ação de dissídio coletivo. De fato, esse pioneirismo decorreu das próprias características do Direito do Trabalho, que contribui para a coletivização dos interesses, mas também dela resulta.

$\mathrm{O}$ acesso qualificado à justiça do trabalho é essencial para o combate de violações constitucionais de enorme gravidade, como são o trabalho infantil e o trabalho em 
condições análogas a de escravo. O combate adequado a essas práticas impõe ação efetiva, no sentido de reparar os danos provocados, mas também inibir a sua ocorrência no futuro, inclusive pela imposição de políticas públicas. Caso a violação não seja atacada na sua integralidade, abre-se a porta para a reincidência.

\section{ACESSO QUALIFICADO À JUSTIÇA DO TRABALHO}

Há demandas da sociedade e conflitos de interesses que exigem respostas e providências que só são adequadas quando oferecidas pela via coletiva. A previsão de inúmeros instrumentos coletivos no texto constitucional e o reforço na atuação dos sujeitos legitimados a manejá-los é, por um lado, resultado do aprofundamento e maturação de estudos realizados pela doutrina, mas também a identificação, pelo constituinte originário, de situações de violações sistemáticas de direitos que dizem respeito a grupos de pessoas. A Constituição de 1988 confere, dessa forma, um conjunto de mecanismos voltados para a tutela coletiva, bem como estabelece as condições para o seu funcionamento satisfatório.

$\mathrm{O}$ acesso qualificado a justiça talvez seja a providência mais audaciosa prevista na Constituição para lograr as transformações nela impostas, decorrente da realização dos valores e princípios constitucionais. Ao lado dos atores do mundo do trabalho aos quais é assegurado o acesso geral à justiça, trabalhadores e empregadores, a Constituição prevê acesso qualificado à Justiça do Trabalho a pelo menos duas instituições constitucionais, ao Ministério Público do Trabalho e aos sindicatos.

Enquanto o acesso previsto no artigo $5^{\circ}, \mathrm{XXXV}$, da Constituição constitui direito fundamental que assegura ao interessado levar qualquer tipo de pretensão ao conhecimento do Judiciário, seja de caráter individual ou coletivo, patrimonial ou não, o acesso qualificado está relacionado também a esse dispositivo constitucional, mas não se restringe a ele. $\mathrm{O}$ acesso qualificado proporciona a concentração de diversas demandas, além da busca de reação adequada aos mais variados descumprimentos das normas jurídicas. $\mathrm{O}$ acesso à justiça pelo Ministério Público do Trabalho e pelos sindicatos reforça essa perspectiva de complementariedade. O sindicato pode defender qualquer modalidade de interesse individual ou coletivo da categoria, nos termos do artigo $8^{\circ}$, III, da Constituição ${ }^{4}$, enquanto o Ministério Público atua para perseguir a tutela de interesses que possuem

\footnotetext{
4 O artigo $8^{\circ}$, III, da Constituição estabelece que ao "sindicato cabe a defesa dos direitos e interesses coletivos ou individuais da categoria, inclusive em questões judiciais ou administrativas".
} 
repercussão social, nos termos do artigo 127 da Constituição ${ }^{5}$. Qualquer restrição que exista em relação à atuação do Ministério Público, na defesa dos interesses que estão sob a sua guarda, afronta não apenas o artigo $5^{\circ}, \mathrm{XXXV}$, mas, sobretudo, os artigos 127 e seguintes, da Constituição. Igual afirmação pode ser feita em relação aos sindicatos. Obstar o seu acesso à justiça acarreta violação, além do artigo 5, XXXV, do artigo $8^{\circ}$, III, da Constituição.

Inicialmente, houve enorme resistência por órgãos do Poder Judiciário trabalhista às ações do Ministério Público do Trabalho e dos sindicatos, como se as mudanças não houvessem sido previstas, ou que sim, mas de maneira bastante atenuada em relação ao que efetivamente contém no texto constitucional. Passado algum tempo, é possível perceber um processo em que essas mudanças impostas no texto constitucional são processadas paulatinamente, com aceitação bem maior das ações ajuizadas pelos atores encarregados da defesa dos direitos e interesses existentes no mundo do trabalho. Apesar dos avanços, as resistências não cessaram completamente e de tempos em tempos ressurgem com força para impedir a redistribuição de poderes na sociedade brasileira, por meio do acesso mais amplo aos valores e bens constitucionais.

Os Juízes possuem importante papel político de inovar e promover transformações na sociedade, antes inadmissível ao Judiciário. Considerando que as violações constitucionais ocorrem não só por ação, mas também por omissão, atuações mais incisivas, inclusive ultrapassando alguns limites antes estabelecidos, podem ser eficazes para provocar os poderes públicos a adotarem providências necessárias para a efetividade dos direitos sociais. Num contexto de ausência de acesso efetivo aos direitos, não se justifica qualquer devoção ao princípio constitucional da separação de poderes, para conter atuação mais contundente do Judiciário. A previsão de que cabe ao Legislativo a determinação de parâmetros para os comportamentos sociais e ao Judiciário incumbe resolver os conflitos de interesses com observância rigorosa das pautas estabelecidas pelos legisladores não é isolada, mas convive com outros princípios constitucionais. O compromisso com a segurança jurídica, numa sociedade carente da fruição dos direitos básicos, reforça a manutenção do status quo, o que representa grave violação ao texto constitucional, na medida em que inviabiliza as mudanças para se chegar ao modelo de sociedade que a Constituição projeta. Não se trata de apropriação

5 De acordo com o artigo 127 da Constituição o "Ministério Público é instituição permanente, essencial à função jurisdicional do Estado, incumbindo-lhe a defesa da ordem jurídica, do regime democrático e dos interesses sociais e individuais indisponíveis". 
de margem para estabelecer, ao lado do legislador, padrões de conduta, mas de zelar pelos direitos previstos no ordenamento jurídico e por mecanismos ágeis que os tornem realidade.

A convicção pelos membros do Judiciário trabalhista acerca da possibilidade e da necessidade da tutela coletiva constitui condição para a efetivação dos instrumentos coletivos previstos na Constituição. Uma interpretação conforme a Constituição implica o reconhecimento de sujeitos, interesses, direitos e bens coletivos (LÓPEZ CALERA, 2000), bem como novos instrumentos, procedimentos e sanções compatíveis com os desafios das sociedades contemporâneas.

Em estudo sobre o processo de constitucionalização do Direito, Ricardo Guastini (2001, p. 153) trata das condições estruturais para a existência desse processo, que são constituição rígida e sistema de controle de aplicação das normas constitucionais. As condições estruturais são necessárias para a existência do processo de constitucionalização do Direito, mas não suficientes para determinar o seu avanço. É por meio de condições complementares que é possível aferir se o processo de constitucionalização do direito encontra-se em estágio mais ou menos avançado. As condições complementares, ao contrário das estruturais, estão na consciência dos integrantes da comunidade jurídica e da sociedade em geral. São convicções compartilhadas acerca da força normativa dos dispositivos constitucionais, da vinculação dos direitos sociais, da eficácia não apenas vertical, mas também horizontal dos direitos fundamentais, da interpretação da Constituição que considere incluída em seu corpo, ainda que de maneira não expressa, todos os aspectos relevantes da vida social e política e, por fim, da interpretação da integralidade do ordenamento jurídico conforme a Constituição. Quanto maior a consciência dos intérpretes em torno desses pontos, mais adiantado se encontrará o processo de constitucionalização do direito.

O processo de coletivização das ações pode se inserir nas condições do processo de constitucionalização do direito, uma vez que contribui para a efetividade dos dispositivos constitucionais e do ordenamento em geral. As condições estruturais para a coletivização das ações encontram-se na Constituição de 1988, ao prever, em seus dispositivos, inúmeros instrumentos para a tutela coletiva, bem como no ordenamento infraconstitucional que a complementa. Porém, o avanço desse processo depende de condições complementares, que correspondem à consciência dos intérpretes em torno da necessidade de se dar abrangência aos instrumentos coletivos previstos, para fins de maior racionalidade da prestação jurisdicional, adequação das respostas oferecidas às demandas da 
sociedade e celeridade na solução dos conflitos trabalhistas. Inserem-se nas condições complementares para o avanço desse processo a assunção das novas responsabilidades dos agentes públicos e atores sociais e, principalmente, a convicção da necessidade de se adotar posturas proativas contra situações de paralisia.

Em suma, a inserção da tutela coletiva no cotidiano da Justiça do Trabalho impõe uma mudança de mentalidades e de práticas. Os atores do mundo do trabalho devem estar comprometidos com a efetividade dos direitos sociais dos trabalhadores e, consequentemente, com os instrumentos de tutela coletiva. A tarefa não é simples, tampouco se realiza satisfatoriamente por meio de ações isoladas. Ela deve converter-se em prática coletiva e levar em conta o papel dos diversos atores, mediante a promoção dos direitos sociais e da dignidade do ser humano.

\section{CONSIDERAÇÕES FINAIS}

A Constituição brasileira de 1988 trouxe inúmeros instrumentos coletivos de atuação e reforçou o poder dos legitimados para acioná-los. Há muito espaço para avanços, considerando as desigualdades nas relações de trabalho e situações que representam graves violações à Constituição e às leis. A solução pontual, ou desde uma perspectiva individual, desses problemas não tem sido capaz de reverter o quadro que se mostra em desconformidade com os valores constitucionais. $\mathrm{O}$ acesso qualificado à justiça possui as condições para assegurar a realização desses valores. Extrai-se do seu conceito não apenas o quantitativo de casos resolvidos na tutela coletiva, mas também a qualidade do resultado. A resolução de demandas coletiva de forma individualizada e fragmentada desvirtua a tutela e não ataca o problema como um todo.

A implementação e consolidação do acesso qualificado à justiça passa por uma reforma estrutural, exigindo mudanças de cultura e mentalidade, principalmente por parte dos atores do Estado. Trata-se de medida constitucional necessária, com potencial a ser mais explorado, sobretudo em períodos de estagnação, ou até retrocesso, no processo de constitucionalização do direito.

Além da maior racionalidade da atividade de resolução de conflitos trabalhistas, o acesso qualificado à justiça assegura, de forma mais eficiente, as medidas necessárias contra ameaças ou violações a direitos trabalhistas. A resolução na perspectiva coletiva propicia também maior participação e inclusão sociais, impulsionando a realização 
dos princípios democráticos.

\section{REFERÊNCIAS}

AÑON ROIG, Maria José y García Añon, José García. VVAA. Lecciones de derechos sociales. Valencia: Tirant lo Blanc, 2004.

ALMEIDA, Gregório Assagra. Direitos fundamentais e os principais fatores de legitimação social do Ministério Público no neoconstitucionalismo. Teoria Geral do Ministério Público. Org. Gregório Assagra de Almeida e Jarbas Soares Júnior. Belo Horizonte: Del Rey, 2013.

BRASIL. [Constituição (1988)]. Constituição da República Federativa do Brasil de 1988. Brasília, DF: Presidência da República, [2016]. Disponível em:

http://www.planalto.gov.br/ccivil 03/Constituicao/Constituiçao.htm. Acesso em: 1 jan. 2017.

BRASIL. Lei $n^{o}$. 8.078, de 11 de setembro de 1990. Código de Defesa do Consumidor. Dispõe sobre a proteção do consumidor e dá outras providências. Disponível em:

http://www.planalto.gov.br/ccivil_03/Leis/L8078.htm. Acesso em 1 jan. 2017.

CAPPELLETTI, Mauro e GARTH, Bryant. Acesso à Justiça. Trad. Ellen Gracie Northfleet. Porto Alegre: SAFE, 1988.

FISS, Owen. The law as it could be. New York, London: New York University Press, 2003.

GIDI, Antonio. Coisa julgada e litispendência em ações coletivas: mandado de segurança coletivo, ação coletiva de consumo, ação coletiva ambiente, ação civil pública, ação popular. São Paulo: Saraiva, 1995.

GIUGNI, Gino. Diritto Sindacale. Bari: Cacucci Editore, 2001.

GUASTINI, Ricardo. La “constitucionalización” del ordenamiento jurídico: el caso italiano. Estudios de teoría constitucional. México. Instituto de investigaciones jurídicas. 2001.

GRINOVER, Ada Pellegrini et all. Código Brasileiro de Defesa do Consumidor. Comentado pelos Autores do Anteprojeto. 8 ${ }^{\text {a }}$ Ed., Rio de Janeiro, Forense Universitária, 2004.

HABERMAS, Jürgen. Acerca de la legitimación basada en los derechos humanos. La constelación posnacional. Ensayos políticos. Barcelona, Paidos, 2000.

HERNÁNDEZ, Jesús María Casal. Aspectos conceptuales del acceso a la justicia. Acceso a la justicia. La universidad por la vigencia efectiva de los derechos humanos, Caracas, Instituto Interamericano de Derechos Humanos, 2006.

JÁUREGUI, Gurutz. Derechos individuales versus derechos colectivos: una realidad inescindible. In: ROIG, F. J. Ansuátegui. Una discusión sobre derechos colectivos. Madrid: 
Dykinson, 2001.

NERY JÚNIOR, Nelson. A ação civil pública no processo do trabalho. In: Ação Civil Pública. Lei 7.347/1985.15 anos depois. Coord. Édis Milaré. 2a. ed., São Paulo, Revista dos Tribunais, 2000.

LEAL, Márcio Flávio Mafra. Ações coletivas: história, teoria e prática. Porto Alegre, SAFE, 1998.

LOPEZ CALERA, N. ?sovitceloc sohcered yaH; Individualidad y socialidad en la teoría de los derechos. Barcelona, Ariel, 2000.

VAROL, Ozan. Structural Rights, 105 GEO. L.J. 1001 (2017).

PEREIRA, Ricardo José Macedo de Britto. Ação Civil Pública no Processo do Trabalho. $2^{\mathrm{a}}$. ed., Salvador: Juspodium, 2018.

SANTOS, Ronaldo Lima dos. Interesses transindividuais: conceito, delineamento e enquadramento na tipologia dos direitos humanos. Estudos aprofundados MPT. Ministério Público do Trabalho. Org. Élisson Miessa e Henrique Correa. 2a. ed., Salvador, Ed. Juspodivm, 2015.

WATANABE, Kazuo. Acesso à Justiça e sociedade moderna. Participação e Processo. Coord. De Ada Pelegrini Grinover, Cândido Rangel Dinamarco e Kazuo Watanabe, São Paulo, Ed. Revista dos Tribunais, 1988. 